\title{
The Impact of Exited Pollutants of Cement Plant on the Soil and Leaves of Trees Species: A Case Study in Golestan Province
}

\author{
Mahdi Farzadkia1, Mitra Gholami', Ehsan Abouee ${ }^{1 *}$, Zahra Asadgol' ${ }^{1}$, Shahram Sadeghi², \\ Hossein Arfaeinia ${ }^{1}$, Maryam Noradini ${ }^{3}$ \\ ${ }^{1}$ Department of Environmental Health Engineering, School of Public Health, Iran University of Medical Sciences, \\ Tehran, Iran \\ ${ }^{2}$ Student Research Committee, Kurdistan University of Medical Sciences, Sanandaj, Iran \\ ${ }^{3}$ Department of Environmental Health Engineering, Faculty of Public Health, North Khorasan University of \\ Medical Sciences, Bojnurd, Iran \\ Email: "ehsan.abouee@gmail.com
}

Received 24 April 2016; accepted 28 May 2016; published 31 May 2016

Copyright (C) 2016 by authors and Scientific Research Publishing Inc.

This work is licensed under the Creative Commons Attribution International License (CC BY). http://creativecommons.org/licenses/by/4.0/

c) (7) Open Access

\begin{abstract}
Background \& Aims: Cement industry is very contaminated. Contaminants resulting from industries include dust, carbon compounds, sulfur and nitrogen. The purpose of this study was to evaluate the output of pollutants from cement plants in soil samples and leaf tree species. Methods: This study descriptive-analytic was designed tree species, plants and soil around the plant. Samples from four different stations within $\mathbf{5 0 0}$ meters of factory and 21 packages (each package contains three examples of the sample) were sent for laboratory tasks. Information of sampling stations in the soil, the plants and factories of qualitative and quantitative tests on samples of soil pollutants output of factories, plant species and trees daily and using written lists were collected. After the sampling, the samples were measured using standard methods and analyzed using statistical software. Results: Distribution of the total amount of metals in oak and black plants and reed Talo is normal and can be used for parametric tests. Also, there is no significant relationship statistically among the total amount of metals in plants such as oak trees, reed and Siah Talo. Conclusions: According to the findings of this study, we can conclude that dust subsides the leaves of three species of oak and black Talo and reed which contain considerable concentrations of metals such as silver, barium, bismuth, cesium, chromium, cobalt, cadmium and arsenic.
\end{abstract}

\section{Keywords}

Cement, Pollutants, Tree Species, Golestan Province

${ }^{*}$ Corresponding author.

How to cite this paper: Farzadkia, M., Gholami, M., Abouee, E., Asadgol, Z., Sadeghi, S., Arfaeinia, H. and Noradini, M. (2016) The Impact of Exited Pollutants of Cement Plant on the Soil and Leaves of Trees Species: A Case Study in Golestan Province. Open Journal of Ecology, 6, 404-411. http://dx.doi.org/10.4236/oje.2016.67038 


\section{Introduction}

In dry and semi-arid ecosystem, contaminants act with greater intensity and entered damage restoration is more difficult. On the other hand, the existing plant communities in these marginal areas are weak, fragile and negligible and with small production they have less resistance compared to the effects of contaminants and if they are to be put in a concentration out of the damage threshold, they will be destroyed with a double intensity [1]. Therefore, in order to maintain and revive it in addition to the correct management of pastures, it is necessary to examine the effects of industrial pollutions on the rangelands of influence spheres [1].

In a major research on the effect of pollutant substances on the vegetation performed in areas around the cement industry in most parts of the world, clearly, the destruction of plant life by the rising material entry has been proved. The emissions from cement factories toward the nature via weather, water and soil that are included as the feeder sources of plant and their concentration beside the plant disturbs their metabolic activities in providing the vital needs. Environmental fluctuations, including temperature, $\mathrm{pH}$, soil moisture and erosion as a result of around pollutants will be created. That along with it, supply of energy resources to the different components of the soil will be placed under this metamorphosis, and the more specialized the vital organs, such as the contents of the plant's chlorophyll, fitomas, protein and starch will show a serious reduction [1]. These dust mites in addition to the various poisonous heavy metals concentration to the plant components make changes in the plant's soil nutrition that their most important items are soil pH due to the arrival of alkaline compounds and the increase of absorption capacity for soil [1]. Mercury and Cadmium are regarded as a heavy poisonous metal and important environmental pollution factor, which are the major source of pollution and produce the most dangerous pollutants by the growth of industry \& cement factories. Whenever the density of pollutants exceeds a certain limit, in addition to the human and animals' health, it can be toxic for plants too. This toxicity is associated with the plant growth reduction and then the yield of plant will be reduced and in more extreme circumstances leads to death [2] [3].

From the past till now, plants were used as the natural bio-monitors for determining the amount of air pollution. Because the plants were able to absorb number of pollutants via their own aerial shoot specially leaves and store in their own, therefore, plant biomonitoring is an appropriate method for estimation of pollutants [4].

The cement industry is one of the 17 most pollusive industries that are listed by Central Pollution Control Board [5]. This industry with the production of abundant pollution plays an important role in the sky's balance and sustainability bashing. The cement as the main components of construction industry is produced in large amounts all over the world [6]. The establishment of factories executes hard rules of the industrial areas earlier than the deadline. Hence, their proximity to residential areas is an important concern at the moment. Generally, the cement dust deposition upon the pasture plants causes loss of energy stored in plant tissues that the yield of plants is reduced in livestock feeding [7].

In Karachi, the cement seriously jeopardized the vegetation around the region; three species including Azadirachta indica, Caressa caradas and Delonix regia were evaluated under the pollution test, such that of any species a sample was contaminated with cement dust and other samples as a control sample were examined. Thus, clearly the effect of rising dusts on plant behavior is observed. It mean that the number of leaves, plant's low growth height and sparse vegetation as a result of the entry of pollutants into the biochemical system of plant and impressing the elements such as chlorophyll and stoma will be there. The point that should be noted is that the susceptibility of different species of the pollutants is not the same. In other words, a plant species may show weaknesses in cases where no changes for other species can be observed. In fact, the sensitivity of different plants to the various pollutants is different [1]. Bertoldi et al, at the 2012 in two cities of Italy examined the impacts of cement industry pollution on the health of the population of the nearby plants, and found that this industry has very harmful impacts on the health and lives of plant population close to the factory. Also, Iran is one of the few countries that seek the development of the cement industry with great seriousness, so that cement production capacity reached in 1335 of 13 thousand tons to 42 million tons in 1386 . This amount is the highest production rate in the Middle East. The policy of the Ministry of Industry and Minerals is stated to double the cement production rate to 60 million tons per year by the year 1400 and per capita cement production expected to be increased from 600 during this period. Meanwhile, Iran's population will exceed 100 million people to next 14 years [8]. Golestan province in with area of 2.2 million hectares where of total area about 1,126,000 hectares was rangeland and 430,000 hectares was forest and in total, forms about 70 percent of the province's natural resources. On behalf of the North with the Republic of Turkmenistan with a 205-km common border, 
that its $120-\mathrm{km}$ is formed of water border by Atrak River and neighbouring from the South with Semnan province and from the East with the North Khorasan province and from the West with the province of Mazandaran. Peyvand cement factory of Golestan was located at 6-km of Galikash city from the cities of Golestan province and is situated at the foot of Nil mountain from the Alborz mountain range [Figure 1]. Suitable mineral resources and market potential and the human resources area and proximity to huge markets in Central Asia and other effective economic factors provided the basis for the establishment of industries including cement plants in the region.

Other studies have shown that the factory has started after preliminary and additional studies about the mines of raw materials and now after getting the required licenses and by making a contract with contractors and advisors, executive operations project is performing. The nominal capacity of the factory in the first phase is 3300 tons per day and space for the construction of a second production line is also anticipated. According to the mentioned content that reflected the increasing development of the cement industry in the country, and since these industries under their effect potentially polluted the environment, with more research we discovered that

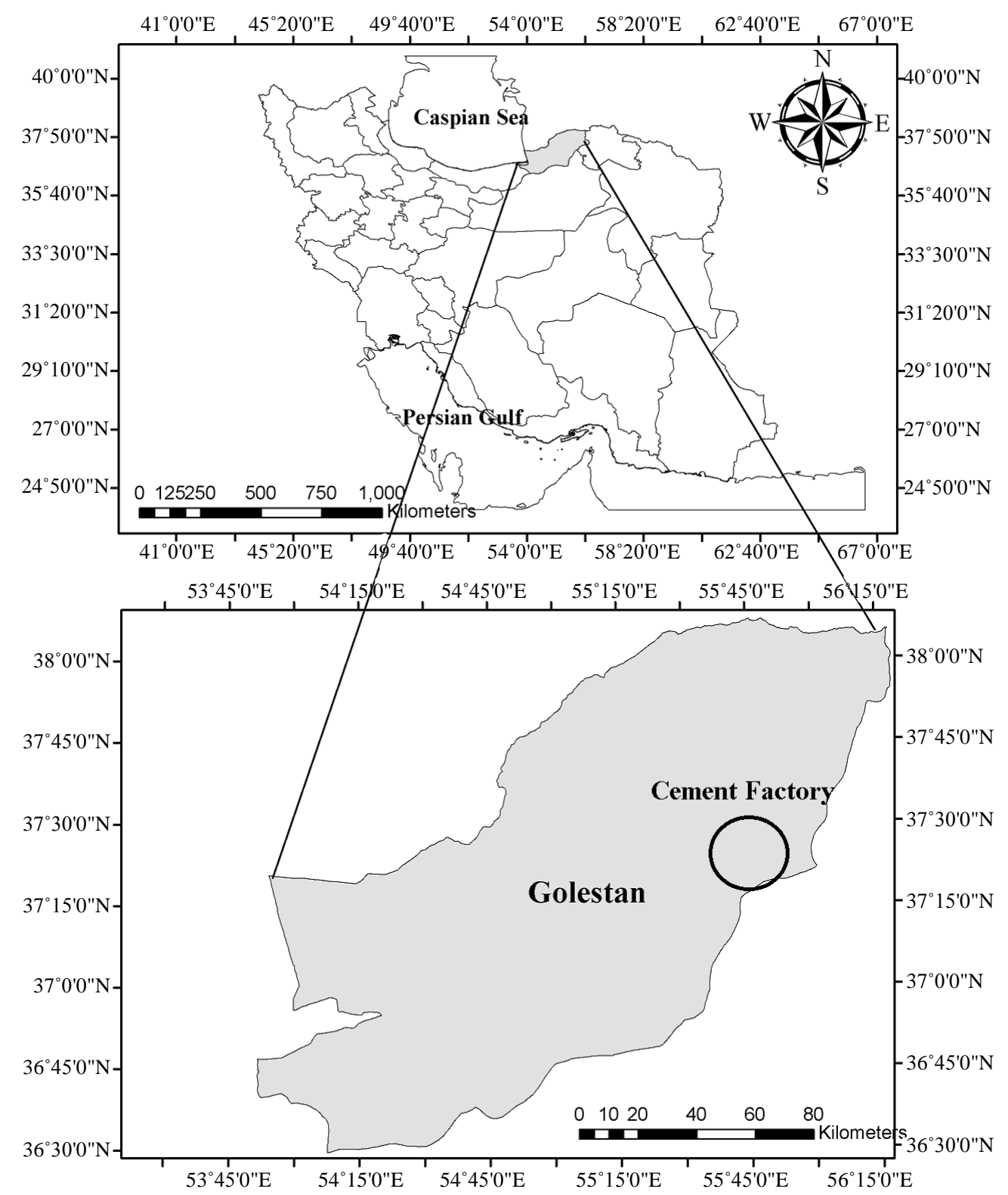

Figure 1. The study area and sampling stations. 
the amount of the output of the cement factory with the help of soil samples and the leaves samples of the tree species were measured and evaluated.

\section{Methods and Materials}

\subsection{Study Area and Sampling}

Type of study was a descriptive analytical case that conducted on tree species, plants and soils around the factory. The factory is away $1100 \mathrm{~km}$ from human communities and $2200 \mathrm{~m}$ from the main transit road and $5 \mathrm{~km}$ from the nearest town and the second town close to the cement factory about $7.5 \mathrm{~km}$ and $12 \mathrm{~km}$ from Golestan forest [Figure 2]. Soil samples from farm lands were obtained by digging with a stainless steel auger. Particles that do not related to soil such as stones, wooden pieces, organic debris and rocks were removed. Samples of fresh plant and trees were obtained from study areas [9]. Examples of 4 different stations with 500 meters distance from the factory and 21 sample pack that each package contains 3 samples which was sent for laboratory work. Information on the type of soil sampling sites, plants surrounding factories and quantitative and qualitative tests on emission pollutants from factories upon soil samples, plants and trees species on a daily basis using the compiled check list, was collected.

\subsection{Digestion and Analytical Procedures}

After sampling, samples were measured by standard methods [10]. Samples were digested by a mixture of $\mathrm{HNO}_{3}, \mathrm{H}_{2} \mathrm{SO}_{4}$ and $\mathrm{HClO}_{4}$ at ratio of 5:1:1 at $110^{\circ} \mathrm{C}$ until the solution would be transparent. The concentrations of metals were determined by using inductively coupled plasma atomic emission spectroscopy [ICP-AES, Arcos model, Germany]. Stock standard solutions containing $200 \mathrm{mg} / \mathrm{l}$ for metal were used for preparing working standards.

\subsection{Statistical Analysis}

After recording the test results and parameters in the check list entered the computer and using SPSS and Excel software were analyzed. To analyze the data, were used of descriptive and inferential statistics. Descriptive statistics include tables and diagrams comparing the average amount of silver, arsenic, cadmium, cobalt, chromium, cesium, bismuth and barium in, oak, Siah Tello plants and straw according to ppm. In inferential statistics to determine the normal distribution of the metals silver, arsenic, cadmium, cobalt, chromium, cesium, bismuth and

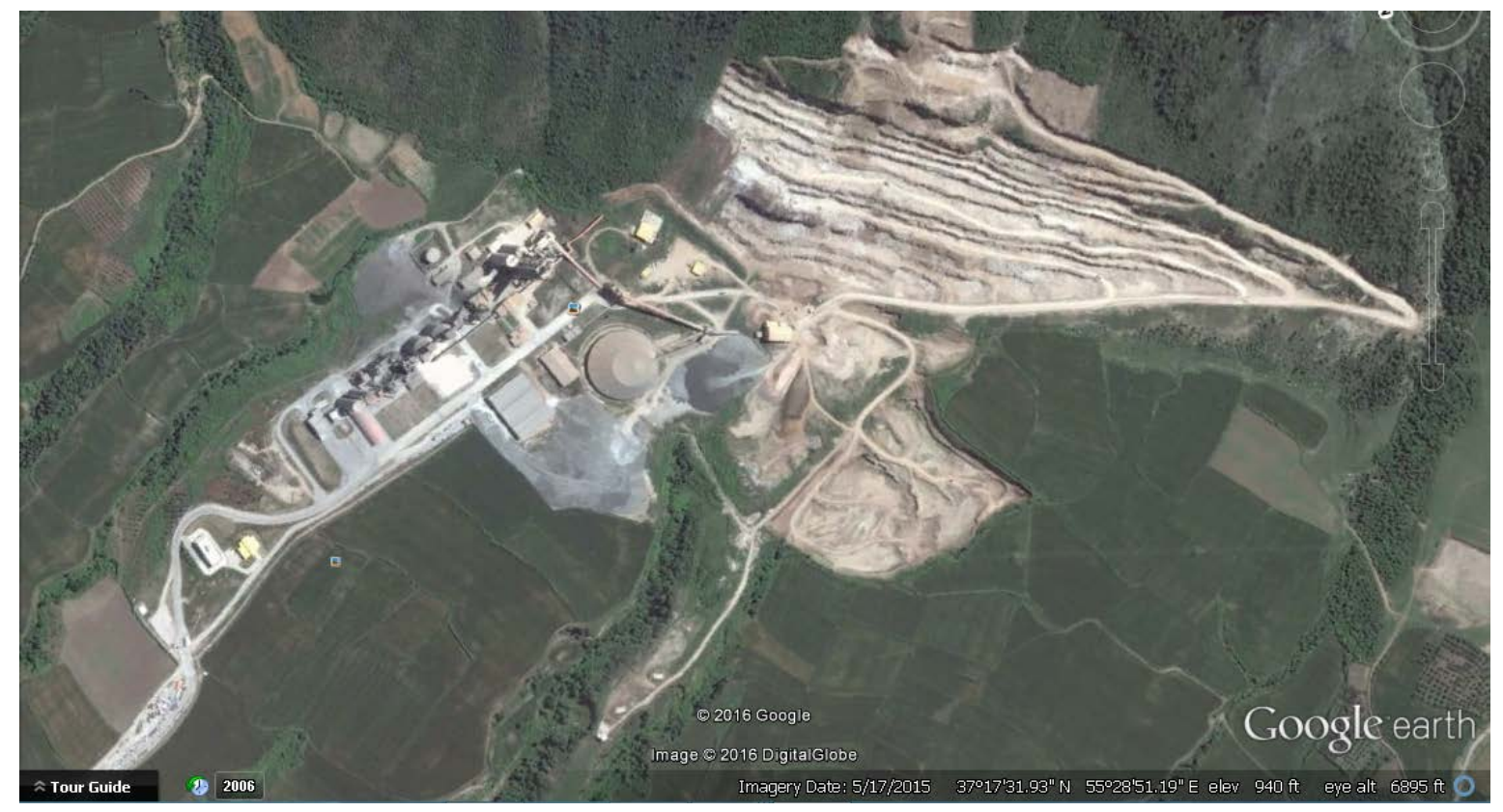

Figure 2. The aerial map from study area and sampling stations. 
barium, according to ppm, in the oak, Siah Tello and reed was used of the KS test and to determine the difference rate of silver, arsenic, cadmium, cobalt, chromium, cesium, bismuth and barium, according to ppm, in the oak, Siah Tello and reed was used of one-way ANOVA.

\section{Results and Discussion}

To determine the extent of the distribution normality of metals amount in oak, and Siah Tello and reed was used of KS test. Table 1 shows statistics of mean and median and Z score of KS and significance level of silver, arsenic, cadmium, cobalt, chromium, cesium, bismuth and barium for the oak and Siah Tello tree and reed. As you seen, the calculated $\mathrm{Z}$ value for all the metals in oak, and Siah Tello and reed was less than 1.96, they also have significant levels lower than 0.025 to test two domains.

Several studies in the field of the role of cement factories on the environment and the creation of air pollution and its devastating effects on crops were performed [5]. Pollutants emitted from cement plants are often transported by wind to distant sites, and depending on the wind velocity at different distances from the plant are sequestrated on the soil, vegetation or residential area. However, these particles are spread from factories based on the size of the particles [11].

As seen in the results, the factory cement leads to higher metals such as silver, arsenic, cobalt, cadmium, etc. in vegetables. Metals in dust of cement plants play an important role in reduction of plant metabolic processes. In addition, the pollution emitted from the cement factory contain dozens of toxic compounds such as fluoride, sulfuric acid, hydrochloric acid, lead, zinc, copper, manganese [12]. As seen in Table 1, the highest mean

Table 1. The statistics about mean and median and Z score in KS test and significance level for the oak and Siah Tello and reed plants.

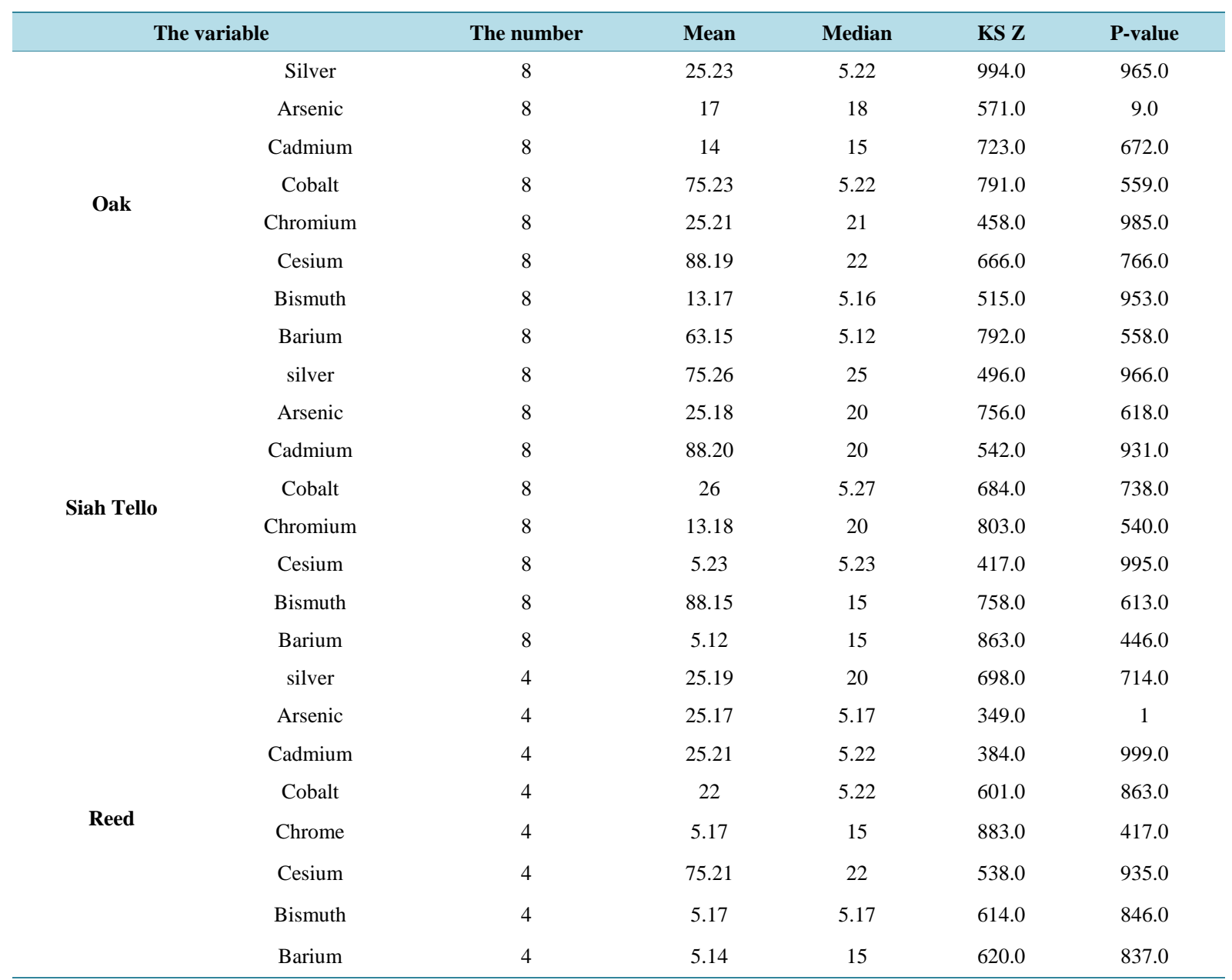


amount of silver, arsenic, cobalt, cesium, barium on a scale of ppm, is in the black plant and the maximum amount of cadmium, bismuth, on a scale of ppm in reed plant, and the maximum average of Chrome, on a scale of ppm, is in the oak tree. To determine the normality of the distribution of metals in plants, oak, Siah Tello and reed were used of KS test and Z value calculated according to Table 1 for all metals in oak and Siah Tello plants and reed less than 1.96 and their significance level also is lower than 0.025 for two-tailed test. It is also a little distance between the mean and the median and so we conclude that the distribution of the amount of these metals is normal in the oak and Telo and Nee black plants and can be used of parametric test there.

Ade-Ademilua have addressed in 2008 to cement dust pollution impact on their spinach plants and found that the concentration of calcium and iron in the infected plants is very high as well as a large accumulation of metals like aluminum, copper and zinc in plants causes dramatically decrease during the germination and total area of desired plant's leaves and in this way, planting and cultivating the vegetables in contaminated areas to cement dust is not recommended at all [13]. AL-oud et al., in the year 2011 have examined thirty-two the dusty compounds and thirty plant examples of a region around a cement factory in the South of the city of Riyadh [capital of the Saudi Arabia] and found that a lot of relatively high content $\mathrm{Cd}, \mathrm{Cr}, \mathrm{Pb}, \mathrm{Cu}, \mathrm{Zn}, \mathrm{Al}, \mathrm{Fe}$ in the soil and plant samples have been seen and statistically a significant relationship between the concentrations of metals available in and plant samples in the soil from a cement factory [14].

Table 2, shows the total value of silver, cadmium, cobalt, chromium, cesium, barium, bismuth in ppm scale in the oak tree, Siah Tello plant and reed which were specified with a one-way variance analysis test of ANOVA specified. From the table amounts, because the calculated $\mathrm{F}$ is smaller for the total amount of metals [F = 1.787] with 17 freedom degrees of 17 and $\mathrm{df}=2$ in confidence level of $95 \%$ [ $\alpha=0.05]$ of $\mathrm{F}$ in the critical table $[\mathrm{F}=$ 3.59]. Therefore, the results may suppose that the difference between the average total amount of metals in the oak tree and Siah Tello plants and reed statistically is not significant. In other words, the extent of absorption of metals is similar in the oak tree and the Siah Tello plants and reed.

In accordance with the Table 3, because only the calculated number $\mathrm{F}$ is greater for cadmium level [F $=4.123]$

Table 2. One-way ANOVA for the average amount of metals in oak and Siah Tello and reed plants.

\begin{tabular}{cccccc} 
& SS & df & MS & F & P-value \\
\hline Intergroup & 45.1124 & 2 & 225.562 & 787.1 & 197.0 \\
Within group & 75.5347 & 17 & 574.314 & & \\
\hline
\end{tabular}

Table 3. One-way ANOVA for the average amount of metals in oak and Siah Tello and reed plants.

\begin{tabular}{|c|c|c|c|c|c|c|}
\hline & & SS & df & MS & $\mathbf{F}$ & P-value \\
\hline \multirow{2}{*}{ Silver } & Intergroup & 8.154 & 2 & 4.77 & \multirow{2}{*}{65.0} & \multirow{2}{*}{535.0} \\
\hline & Within group & 75.2025 & 17 & 162.119 & & \\
\hline \multirow{2}{*}{ Arsenic } & Intergroup & 7.6 & 2 & 35.3 & \multirow{2}{*}{124.0} & \multirow{2}{*}{884.0} \\
\hline & Within group & 25.458 & 17 & 956.26 & & \\
\hline \multirow{2}{*}{ Cadmium } & Intergroup & 575.235 & 2 & 788.117 & \multirow{2}{*}{123.4} & \multirow{2}{*}{035.0} \\
\hline & Within group & 625.485 & 17 & 566.28 & & \\
\hline \multirow{2}{*}{ Cobalt } & Intergroup & 7.46 & 2 & 35.23 & \multirow{2}{*}{808.0} & \multirow{2}{*}{462.0} \\
\hline & Within group & 5.491 & 17 & 912.28 & & \\
\hline \multirow[t]{2}{*}{ Chromium } & Intergroup & 375.54 & 2 & 188.27 & \multirow{2}{*}{225.1} & \multirow{2}{*}{318.0} \\
\hline & Within group & 375.377 & 17 & 199.22 & & \\
\hline \multirow{2}{*}{ Cesium } & Intergroup & 575.52 & 2 & 288.26 & \multirow{2}{*}{724.0} & \multirow{2}{*}{499.0} \\
\hline & Within group & 625.617 & 17 & 331.36 & & \\
\hline \multirow{2}{*}{ Bismuth } & Intergroup & 45.9 & 2 & 725.4 & \multirow{2}{*}{336.0} & \multirow{2}{*}{719.0} \\
\hline & Within group & 75.238 & 17 & 044.14 & & \\
\hline \multirow{2}{*}{ Barium } & Intergroup & 675.27 & 2 & 838.13 & \multirow{2}{*}{389.0} & \multirow{2}{*}{684.0} \\
\hline & Within group & 875.604 & 17 & 581.35 & & \\
\hline
\end{tabular}


Table 4. Post-hoc Tukey test to determine the significance differences in the amount of cadmium in the samples.

\begin{tabular}{cccc}
\hline Component $\mathbf{j}$ & Component $\mathbf{i}$ & P-value & Mean difference [i-j] \\
\hline Siah Tello & oak & 049.0 & $875 . ._{-}-6$ \\
Reed & & 097.0 & $25 .-7$ \\
Oak & Siah Tello & 049.0 & $875 . * 6$ \\
Reed & & 993.0 & $375 .-0$ \\
Oak & Reed & 097.0 & 25.7 \\
Siah Tello & & 993.0 & 375.0 \\
\hline
\end{tabular}

with 17 degrees of freedom and $\mathrm{df}=2$ in confidence level of 95\% [ $\alpha=0.05]$ of the critical table [F $=2 \pm 0$.$] .$ Therefore, we concluded that the difference between the average of the amount of cadmium in the oak and Siah Tello tree and reed statistically is not significant. But the average amount of other metals in the oak tree and Siah Tello and reed statistically are equal. To determine the average amount of cadmium in which one of the oak tree and Siah Tello and reed will be more than others, we uses of the post hoc Tukey test.

In the table of Tukey [Table 4], a significant difference in any of the averages with other averages in the sub-sections of difference column with the asterisk $(*)$ and sub-sections of P-value column, is specified with a significant level smaller than 0.05. From the amounts in above table, only the amount of cadmium in Siah Tello has a significant difference with oak tree [P-value $=0.035$ ] and on the amount of the table's average turns out to be that the amount of cadmium in Siah Tello plant is more than the oak tree, on other words, Siah Tello had a better absorption of cadmium. It should be noted that the average amount of cadmium in Reed plant is more than others, but because the number and standard deviation in reed samples is very different. Tukey test did not have a significant difference. Obadola have been told that the canopy of the trees' ability is very better than others to capture and sequestrate existing particles in the air, and this is due to having more rough leaf surfaces in this category of plants [15].

Increasing the concentration of dust in the air causes severe reduction in the capability of photosynthesis in leaves, closing the orifice of the leaves and mainly growth and decreased fertility of the plants. Sadeghi and Khorasani also realized in 2008, there is the inverse correlation between vegetation density and diversity with the deposition of dust particles emission out of a cement factory and being farther away from particles emission source, the deposition of particles will be reduced and diversity and density of coverage will be increased [8].

\section{Conclusion}

According to the study, it can be concluded that the dust has sat on the leaves of three species of oak and black Tello and reed which contain significant concentrations of metals such as silver, barium, bismuth, cesium, chromium, cobalt, cadmium and arsenic. So away from the factory, the concentration of these elements can be reduced in both species. This means that the highest concentration of these elements is observed near the factory. The arrival of this group of compounds causes not only disorder in the metabolic activities of the plants, but the origin of many dangerous human diseases such as cancer for human. Therefore, it seems necessary that the factories near the residential centers must be of the appropriate filters to prevent the creation of diseases such as cancer, respiratory problems and disorder in the metabolic processes of plants and air pollution and the environment.

\section{Acknowledgements}

This research project sponsored by the Student Research Committee of deputy of Research and Technological University of Medical Sciences was approved to No. 709/P/92 dated 1/07/2013. In this article, the authors thank the respected authorities of the Vice Chancellor for research and Technology University of Medical Sciences, North Khorasan who provide the facilities for this research.

\section{References}

[1] Schuhmacher, M., Domingo, J.L. and Garreta, J. (2004) Pollutants Emitted by a Cement Plant: Health Risks for the Population Living in the Neighborhood. Environmental Research, 95, 198-206. 
http://dx.doi.org/10.1016/j.envres.2003.08.011

[2] Akeredolu, F., Olaniyi, H., Adejumo, J., Obioh, I., Ogunsola, O., Asubiojo, O., et al. (1994) Determination of Elemental Composition of TSP from Cement Industries in Nigeria Using EDXRF Technique. Nuclear Instruments and Methods in Physics Research Section A: Accelerators, Spectrometers, Detectors and Associated Equipment, 353, 542-545. http://dx.doi.org/10.1016/0168-9002(94)91718-3

[3] Arfaeinia, H., Nabipour, I., Ostovar, A., Asadgol, Z., Abuee, E., Keshtkar, M., et al. (2016) Assessment of Sediment Quality Based on Acid-Volatile Sulfide ANd Simultaneously Extracted Metals in Heavily Industrialized Area of Asaluyeh, Persian Gulf: Concentrations, Spatial Distributions, and Sediment Bioavailability/Toxicity. Environmental Science and Pollution Research, 23, 9871-9890. http://dx.doi.org/10.1007/s11356-016-6189-0

[4] Hajrasuliha, S., Hodaji, M. and Najafi, P. (2005) Detected Environmental Pollution and Soil in Isfahan. Research in Agricultural Sciences, 2, 39-54.

[5] Iqbal, M., Jura-Morawiec, J. and WŁoch, W. (2010) Foliar Characteristics, Cambial Activity and Wood Formation in Azadirachta indica A. Juss. as Affected by Coal-Smoke Pollution. Flora-Morphology, Distribution, Functional Ecology of Plants, 205, 61-71. http://dx.doi.org/10.1016/j.flora.2008.12.003

[6] Salama, H.M., Al-Rumaih, M. and Al-Dosary, M. (2011) Effects of Riyadh Cement Industry Pollutions on Some Physiological and Morphological Factors of Datura innoxia Mill. Plant. Saudi Journal of Biological Sciences, 18, 227-237. http://dx.doi.org/10.1016/j.sjbs.2011.05.001

[7] Lal, B. and Ambasht, R. (1982) Impact of Cement Dust on the Mineral and Energy Concentration of Psidium guayava. Environmental Pollution Series A, Ecological and Biological, 29, 241-247. http://dx.doi.org/10.1016/0143-1471(82)90065-4

[8] Karbasi, A.R., Khadem Borojerdi, H.R. and Samadi, R. (2008) The Environmental Impact of Cement Plants Abyek. The 1st International Conference on Cement Industry, Energy and the Environment, Tehran, 20-22 Jun 2013.

[9] Jung, M.C. (2008) Heavy Metal Concentrations in Soils and Factors Affecting Metal Uptake by Plants in the Vicinity of a Korean Cu-W Mine. Sensors, 8, 2413-2423. http://dx.doi.org/10.3390/s8042413

[10] Federation, W.E. and Association, A.P.H. (2005) Standard Methods for the Examination of Water and Wastewater. American Public Health Association [APHA], Washington DC.

[11] Aydin, S., Aydin, S., Croteau, G., Sahin, Í. and Citil, C. (2010) Ghrelin, Nitrite and Paraoxonase/Arylesterase Concentrations in Cement Plant Workers. Journal of Medical Biochemistry, 29, 78-83. http://dx.doi.org/10.2478/v10011-010-0009-8

[12] Al-Omran, A.M., El-Maghraby, E., Nadeem, E., Ali, M. and Al-Qahtani, S.M. (2011) Impact of Cement Dust on Some Soil Properties around the Cement Factory in Al-Hasa Oasis, Saudi Arabia. American-Eurasian Journal of Agricultural \& Environmental Sciences, 11, 840-846.

[13] Ade-Ademilua, O. and Obalola, D. (2008) The Effect of Cement Dust Pollution on Celosia argentea [Lagos Spinach] Plant. Journal of Environmental Science and Technology, 1, 47-55. http://dx.doi.org/10.3923/jest.2008.47.55

[14] Al-Oud, S., Nadeem, M. and Al-Shbel, B. (2011) Distribution of Heavy Metals in Soils and Plants around a Cement Factory in Riyadh City, Central of Saudi Arabia. American-Eurasian Journal of Agriculture and Environmental Science, 11, 183-191.

[15] Princewill, C. and Adanma, N. (2011) Metal Concentration in Soil and Plants in Abandoned Cement Factory. International Conference on Biotechnology and Environment Management IPCBEE, 18, 146-150. 